\title{
Indissociabilidade entre sustentabilidade e Escolas Criativas e suas implicaçóes para religar o ensino à complexidade da vida
}

Levi Hülse ${ }^{1}$

https://orcid.org/0000-0002-9974-6325

Gabriel Real Ferrer ${ }^{2}$

https://orcid.org/0000-0002-6993-3373

Clovis Demarchi ${ }^{3}$

https://orcid.org/0000-0003-0853-0818

Adelcio Machado dos Santos ${ }^{4}$

https://orcid.org/0000-0003-3916-972X

\section{Resumo}

Este artigo resulta de uma pesquisa bibliográfica sobre a relação entre sustentabilidade e Escolas Criativas. Seus autores de referência são Cruz e Bodnar (2011), Ferrer (2013), Hülse (2020), Sachs (2009), Torre (2009, 2013), Petraglia (2013) e Sá (2019). Por meio da abordagem

${ }^{1}$ Doutor e Mestre em Ciência Jurídica pela Universidade do Vale do Itajaí (UNIVALI), área de concentraçāo Constitucionalismo, Transnacionalidade e Produçāo do Direito. Bacharel em Direito pela Fundação Universidade Regional de Blumenau (FURB - 2010) e graduado em História pela Fundaçáo Universidade Regional de Blumenau (FURB - 2006). Advogado com a OAB/SC 31.986. Docente e pesquisador dos Programas de Pós-Graduaçáo em Desenvolvimento e Sociedade e Profissional em Educaçáo da Universidade Alto Vale do Rio do Peixe (UNIARP). E-mail: levi@uniarp.edu.br. Lattes: http://lattes.cnpq.br/1833130032474610.

${ }^{2}$ Doutor em Direito pela Universidade de Alicante (Espanha), professor titular de Direito Ambiental e Administrativo e Subdiretor do Instituto Universitário da Água e do Meio Ambiente na mesma Universidade. Consultor do Programa das Naçóes Unidas (ONU) para o Meio Ambiente (PNUMA). E-mail: gabriel.real@ua.es.

${ }^{3}$ Doutor e Mestre em Ciência Jurídica pela Universidade do Vale do Itajaí (UNIVALI - SC). Professor na graduaçáo em Direito e no Curso de Doutorado e Mestrado em Ciência Jurídica da UNIVALI. Membro do grupo de pesquisa em Direito, Constituição e Jurisdiçăo. Lattes: http://lattes.cnpq.br/9819761828844957. Email:demarchi@univali.br.

${ }^{4}$ Doutor em Engenharia e Gestão do Conhecimento pela Universidade Federal de Santa Catarina (UFSC). Docente e Pesquisador da Universidade Alto Vale do Rio do Peixe (UNIARP) nos Programas de Pós-graduaçăo em Desenvolvimento e Sociedade e Educaçáo. Endereço: Rua Prof. Egídio Ferreira, no 271, Bloco "E”, apto. 303. CEP: 88090-699, Florianópolis (SC), Brasil. E-mail: adelciomachado@gmail.com. 
qualitativa, o estudo elucida dimensóes da sustentabilidade e as aproxima da perspectiva das Escolas Criativas. Os resultados apontam para a indissociabilidade entre sustentabilidade e Escolas Criativas, observada especialmente no contato dos estudantes com o mundo que os cerca e quando as práticas sustentáveis os fazem vivenciar a vida econômica, política, social, cultural e ambiental, alinhando-se o que se trabalha na escola com o que ocorre na sociedade. Palavras-chave: Sustentabilidade, Educação, Escolas Criativas, Dimensóes da Sustentabilidade, Ensino.

\title{
Inseparability between sustainability within the Creative Schools and its applications to rejoin teaching to the complexity of life
}

\begin{abstract}
This paper results from a bibliographical research about the relation between sustainability and the Creative Schools and its referential authors are Cruz e Bodnar (2011), Ferrer (2013), Hülse (2020), Sachs (2009), Torre (2009, 2013), Petraglia (2013), Sá (2019), By means of the qualitative approach, the study highlights the dimensions of sustainability and rejoins them to the perspective of the Creative Schools. The results point to the inseparability between the Creative Schools, specially when it is observed within the students' contact with the world surrounding them and whereas the sustainable practices bring them to live the economic, political, social, cultural and environmental life, aligning that which is worked at the school with what happens in society.
\end{abstract}

Keywords: Sustainability, Education, Creative Schools, Dimensions of Sustainability, Teaching.

\section{Introduçáo}

Este artigo objetiva correlacionar sustentabilidade e suas dimensóes com as Escolas Criativas, destacando condiçôes que as tornem indissociáveis. Como hipótese desta pesquisa, considera-se que a sustentabilidade - aqui representada pelas dimensóes ambiental, econômica e social - contribui positivamente para a melhora da sociedade quando estimulada nas práticas pedagógicas dinamizadas em Escolas Criativas.

$\mathrm{O}$ artigo discute, inicialmente, o conceito de sustentabilidade, destacando as implicações da dimensão tríplice citada. $\mathrm{Na}$ sequência, analisa a relevância de práticas pedagógicas que se utilizam desse conceito, tendo como base a perspectiva das Escolas Criativas.

Constituindo-se como uma pesquisa bibliográfica ancorada no método indutivo, este estudo prioriza o método histórico na fase de tratamento de dados, fundamentando a utilização do método analítico; além disso, faz-se uso 
do método indutivo na fase do relatório dos resultados apresentados. Em todas as fases, utilizaram-se as técnicas do referente, das categorias e dos conceitos operacionais (PASOLD, 2018).

\section{Sustentabilidade}

Sustentabilidade é um tema que vem sendo discutido desde a Conferência das Naçóes Unidas sobre o Meio Ambiente de Estocolmo, em 1972. Naquele momento, a sociedade começou a tomar consciência de que seu desenvolvimento deve ser unido com a preservação do meio ambiente. Cruz e Bodnar (2011, p. 79) assim descrevem o tema:

Dentre os princípios estabelecidos naquela conferência, o primeiro deles previa que o homem tem o direito fundamental à liberdade, à igualdade, ao gozo de condiçóes de vida adequadas num meio ambiente de tal qualidade que permita levar uma vida digna e gozar do bem-estar, e tem solene obrigaçáo de proteger e melhorar o meio ambiente para as gerações presentes e futuras.

Passado esse evento, várias outras iniciativas globais seguiram acontecendo, por exemplo a Assembleia Geral de 1983, a Eco 92, no Rio de Janeiro, e a Declaração do Milênio, com os Objetivos de Desenvolvimento do Milênio em 2000, além da Cúpula Mundial sobre Desenvolvimento Sustentável ou Rio+10, em Johanesburgo em 2002. Após esses eventos, o termo sustentabilidade foi consolidando-se e começou a ser pensando numa tripla dimensão: ambiental, social e econômica (FERRER, 2013).

Esse termo "[...] vem a ser um contraponto ao conceito de crescimento, pois neste tudo era possível fazer para manter a economia dos países e aumentar o capital das pessoas" (HÜLSE, 2020, p. 62). Veiga (2015) lembra que o crescimento tem como objetivo explorar todos os bens naturais, transformando tudo em mercadoria, obtendo, assim, lucro sem qualquer preocupação com os recursos naturais.

Contrapondo-se a essa perspectiva de crescimento, a sustentabilidade vem a representar "[...] procedimentos que tomamos para permitir que a Terra e seus biomas se mantenham vivos, protegidos, alimentados de nutrientes de estarem sempre bem e conservados" (BOFF, 2015, p. 32). Nesse sentido, Ferrer, Glasenapp e Cruz (2014, p. 1457) asseveram que a “[...] 
sustentabilidade tornou-se uma noção positiva e altamente prospectiva, que supóe a introdução de mudanças necessárias para que a sociedade planetária seja capaz de perpetuar-se indefinidamente no tempo e no espaço.”

A sustentabilidade trata-se de princípio constitucional que determina, com eficácia direta e imediata, a responsabilidade do Estado e da sociedade pela concretização solidária do desenvolvimento material e imaterial, socialmente inclusivo, durável e equânime, ambientalmente limpo, inovador, ético e eficiente, para assegurar o bem-estar no presente e no futuro (JUAREZ FREITAS, 2011, p. 40).

Ela deve, portanto, ser pensada e colocada em prática por todos, pois o mundo em que se vive é finito. Caso sejam usados todos os recursos, conforme se prevê nas teorias de crescimento, não haverá recursos para as geraçóes futuras, levando a sociedade a um colapso.

Contudo, a sustentabilidade somente será efetivada se houver uma cooperação entre a sociedade, o estado, as empresas e a sociedade civil organizada. Ao estado compete promover políticas públicas voltadas para a sustentabilidade, especificamente para que as escolas promovam atitudes sustentáveis entre seus alunos, pois esses, mais tarde, serão os atores - nas empresas e na sociedade - que poderão ampliar ainda mais as condiçóes daquilo que valorizaram/protagonizaram nas escolas. Segundo Boff (2015):

A sustentabilidade não acontece mecanicamente. Ela é fruto de um processo de educação pela qual o ser humano redefine o feixe de relaçóes que entretém com o universo, com a Terra, com a natureza, com a sociedade e consigo mesmo dentro dos critérios assinalados de equilíbrio ecológico, de respeito e amor à Terra e à comunidade de vida, de solidariedade para com as geraçóes futuras e da construção de uma democracia socioecológica (BOFF, 2015, p. 149).

Observa-se que a sociedade civil organizada, por meio das Organizaçóes não Governamentais (ONGs), vem se opondo de maneira expressiva à degradação ambiental. Por terem forte atuação entre as populações menos favorecidas socialmente, essas ONGs vêm fomentado a sustentabilidade ambiental e econômica (HULSE, 2020) em uma boa parcela da populaçáo.

Já as empresas, além de gerarem empregos, devem se conscientizar de que o uso de recursos naturais reduzido ao mínimo possível em sua cadeia de 
produção pode ampliar possibilidades para a população em geral. Por fim, o governo precisa desenvolver políticas voltadas para a sustentabilidade e para as escolas que se utilizam de práticas pedagógicas respaldadas por ela.

Assim, a participação de todas as dimensões da sociedade é vital para a efetivação da sustentabilidade. Considerando que o ser humano é um ser social e que, se essa sociedade, por meio de seu contrato social, define como objetivo viver de forma sustentável, todas as suas atitudes serão em prol dessa nova forma de viver.

Entende-se, portanto, a sustentabilidade como “[...] marco civilizatório para o desenvolvimento, produto da razoabilidade do consenso em prol da garantia da sobrevivência humana, devendo assim ser analisada e considerada para efeito de quaisquer iniciativas públicas e privadas" (MACHADO, 2013, p. 12). Conforme Hülse e Pasold (2018, p. 178), “[...] deve-se buscar o equilíbrio da natureza para que o planeta terra venha a se tornar sustentável."

Por fim, destaca-se que “[...] uma sociedade será Sustentável se os seus cidadãos forem socialmente participativos, se cultivarem um cuidado consciente para conservação e regeneração da natureza, tornando-se assim uma comunidade democraticamente ecológica" (HÜLSE, 2020, p. 78).

Os estudos da sustentabilidade, geralmente, dão-se por meio do tripé "ambiental, social e econômico", que muitos autores chamam de dimensóes. Sobre esse tripé, Elkington (2012, p. 108) descreve o Triple Botton Line, a partir do qual considera que as pessoas, o planeta e o lucro devem estar em sintonia com as dimensóes da sustentabilidade. Para esse autor, “[...] a empresas para ser sustentáveis devem ser ambientalmente responsáveis, economicamente viáveis e socialmente justas."

Ressalta-se que existem autores que consideram mais dimensóes, tais como a política, a tecnológica, a espacial ou a ética. Para o presente artigo, utilizar-se-á o tripé já citado.

\section{Dimensão ambiental da sustentabilidade}

A dimensão ambiental da sustentabilidade é a mais estudada e a mais conhecida. Para muitas pessoas, a sustentabilidade é apenas uma questão ambiental, o que evidencia uma lacuna, já que ela vai além dessa especificidade. 
Conforme o Art. 225 da Constituição da República Federativa do Brasil (BRASIL, 2019), o meio ambiente é um direito de todos, um bem de uso comum e para a qualidade de vida de toda população, sendo um direito da coletividade e das geraçốes futuras.

Conforme Denise Garcia (2016, p. 138), a dimensão ambiental:

[...] é aquela em que se observa a importância da proteçáo do meio ambiente e, consequentemente, do Direito Ambiental, tendo este, como finalidade precípua, garantir a sobrevivência do planeta mediante a preservação e a melhora dos elementos físicos e químicos que a fazem possível, tudo em funçấo de uma melhor qualidade de vida.

$\mathrm{Na}$ dimensão ambiental, deve-se ater ao uso racional dos recursos naturais, diminuir a poluição e o lixo, por meio de políticas de redução/reutilização e reciclagem, diminuir o consumo de petróleo, criar normas para a proteção ambiental e aumentar pesquisas para o uso eficiente dos recursos naturais, diminuindo os resíduos (FROEHLICH, 2014). Vale destacar que um meio ambiente degradado não dará qualidade de vida às pessoas, bem como diminuirá a longevidade da população (TONNERA JUNIOR, 2016).

Ressalta-se, desse modo, a importância de um meio ambiente equilibrado, pois a natureza (flora, fauna, ar, água e solo) deve se manter em equilíbrio, uma vez que, ao entrar em desarmonia e sair de seu estado de normalidade, pode gerar o surgimento de epidemias e doenças que venham a atacar toda a população mundial (COLNAGO, 2014), como a pandemia de Covid-19, que vem assolando o mundo em 2020.

Colnago (2014) enfatiza que a natureza náo deve ser considerada um santuário intocável, pois pode e deve gerar riquezas, mas não se pode deixar que a sociedade busque apenas crescimento desordenado e a use sem qualquer cuidado; deve-se usá-la de modo sustentável e planejado, compatibilizando, assim, a proteção ambiental com o desenvolvimento econômico.

\section{Dimensáo econômica da sustentabilidade}

Quando se fala em dimensão econômica da sustentabilidade, devem ser repensados o consumo e a produçáo, pois o meio ambiente não pode ser 
pensado e utilizado como um bem inesgotável, sem que haja qualquer intervenção estatal.

Conforme Ferrer (2013), a sustentabilidade econômica consiste em resolver os desafios de aumentar a geração de riqueza de maneira sustentável e encontrar mecanismos para uma distribuição justa e homogênea. Para essa dimensão ser efetiva, o estado tem um papel fundamental, devendo usar a tributaçáo como meio de preservação dos bens da natureza e como forma de diminuir a desigualdade. Nesse sentido, devem-se tributar os mais ricos para promover programas de distribuição de renda para os mais pobres (HÜLSE, 2020).

Ainda sobre essa dimensão, Stroh (2009, p. 86) também assevera que se deve "[...] ter um desenvolvimento intersetorial equilibrado, segurança alimentar, capacidade de modernização contínua dos instrumentos de produção, inserção soberana na economia internacional."

Só haverá uma sociedade sustentável quando houver orçamentos familiares suficientes a todos, boas condiçôes de trabalho, direito previdenciário e trabalhista eficientes e qualificação profissional à população. "Usar a renda familiar como parâmetro dessa dimensão não será eficaz, isto é, deve-se fazer uma leitura da realidade econômica através da qualidade de vida das pessoas" (HULSE, 2020, p. 90).

\section{Dimensáo social da sustentabilidade}

Quando se pensa numa sociedade, não se pode admitir um modelo excludente, isto é, uma sociedade onde poucos vivem com muito e muitos vivem com pouco. $\mathrm{Na}$ dimensão social da sustentabilidade, devem ser respeitados os direitos sociais previstos no Art. 6 da Constituição, como os direitos à educação, à saúde, à alimentação, ao trabalho, à moradia, ao transporte, ao lazer, à segurança, à previdência social, à proteção à maternidade e à infância, à assistência aos desamparados. Assim Souza (2016, p. 254) conceitua essa dimensão:

A dimensão social atua desde a proteção da diversidade cultural até a garantia real do exercício dos direitos humanos para eliminar qualquer tipo de discriminação ou o acesso à educação, todos recaindo sob essa rubrica. Na perspectiva social, busca-se conseguir uma sociedade mais homogênea e melhor governada, com acesso à saúde e à educação, 
combate à discriminação e à exclusão social. Os direitos humanos se apresentam como tentativa de concretizar essa Dimensão.

Nessa dimensão da sustentabilidade, conforme Ferrer (2013, p. 323), deve-se dar "[...] acesso à educação, à cultura e aos serviços de saúde, ao acesso fácil ao crédito, à renda mínima de inclusão ou aos benefícios de desemprego, bem como haver políticas públicas nesse sentido."

O maior problema a ser enfrentado nessa dimensão são as desigualdades sociais, que se ampliaram com a migração da sociedade para o meio urbano, propiciando a criação das periferias. Considerando que muitos desses locais fora das cidades são desprovidos de equipamentos e de serviços essenciais, torna-se necessário que as cidades impulsionem uma distribuição equânime de seus serviços. Aos trabalhadores, nessa dimensão, devem ser oferecidas políticas de estímulo ao emprego e uma renda mínima (SILVA; SOUZA; LEAL, 2012).

A dimensão social da sustentabilidade será atendida quando se reduzir a pobreza, aumentar a participação da mulher nas relaçóes de emprego, houver respeito aos direitos humanos e houver uma distribuição menos desigual da renda. Para Stroh, será alcançada quando houver "[...] homogeneidade social, distribuição de renda justa, emprego pleno e/ou autônomo com qualidade de vida decente, igualdade no acesso aos recursos e serviços sociais" (STROH, 2009, p. 85).

\section{Educaçáo e sustentabilidade}

A ideia de sustentabilidade, independentemente da dimensão ambiental, econômica ou social, ou qualquer outra que se queira criar, não surge automaticamente ou mecanicamente no pensamento das pessoas. Ela é o resultado de um processo de educação que, para Demarchi (2014), prepara a pessoa para realizar uma análise ampla, com capacidade de relacionar o ser humano com o mundo que o cerca, náo reduzindo sua perspectiva apenas ao saber formal previsto no currículo escolar.

Faz-se importante relembrar que a Organização das Nações Unidas (ONU), em setembro de 2015, buscou adotar, formalmente, uma agenda de desenvolvimento sustentável formada por 17 Objetivos de Desenvolvimento Sustentável (ODS) para garantirem a sustentabilidade do planeta, a serem 
implementados nos 15 anos seguintes, portanto até 2030. Esses objetivos visam pôr fim à pobreza, à desigualdade de gênero, garantir alimentação, água e saneamento, buscar a criação de cidades sustentáveis, ou seja, garantir um desenvolvimento sustentável para todas as pessoas.

Nesse sentido, a educação se faz necessária e se torna elemento angular, visto envolver integralmente todas as pessoas, resultando em não excluídos desse processo. Conforme Demarchi (2014, p. 112), a educação pode ser vislumbrada a partir de duas realidades: uma como "formação" que pensa o "[...] homem como um todo, nas suas relaçôes com o outro, consigo mesmo e com o mundo [...]", ou seja, uma educação informal; outra como educação formal, ou seja, que "[...] implica atividades de ensino, que são apresentadas intencionalmente, com a perspectiva de produzir aprendizagem." Contudo, a segunda realidade pode implicar a primeira, por ser uma educação que produz aprendizagem na relação com o outro, consigo e com o entorno local e global.

Conforme o ODS 4, a educaçáo tem como fundamento assegurar “ [...] a educação inclusiva, e equitativa e de qualidade, e promover oportunidades de aprendizagem ao longo da vida para todos" (ONU, 2015). Portanto, uma educação formal e, também, informal.

A Constituição (BRASIL, 2019) estabelece que a educação é um direito social (art. 6 $6^{\circ}$, caput) e deve ter seu espaço específico (art. 205 ao 214). Mais claramente, o art. 205 estabelece a educaçáo como "direito de todos e dever do Estado e da família", determinando que isso deve acontecer com a promoção e o incentivo da sociedade. A educação tem, então, três objetivos fundamentais: "pleno desenvolvimento da pessoa", "qualificação para o trabalho" e "preparo para o exercício da cidadania".

Destaca-se, dessa forma, que a educação sustentável seria aquela que apresenta por substrato a perenidade, a continuidade, com vistas à manutenção desse direito de todos e para todos como meio de reduçáo de desigualdades, possibilitando seu acesso a todas as pessoas (SACHS, 1990, 2002).

É comum associar educação sustentável à educação ambiental, mas não se pode esquecer que sustentável não é somente a necessidade do meio ambiente, mas da vida do planeta, logo, em todas as suas dimensóes. Assim, o termo sustentabilidade implica perenidade e direito a um futuro 
ecologicamente ${ }^{5}$ equilibrado, um direito que se estende às geraçóes presentes e futuras.

Como essa realidade não se faz mecanicamente ou automaticamente, há necessidade de um processo generalizado de educação para que se criem novas mentes e novas posturas capazes de modificar o contexto em que se vive e de reduzir os riscos globais que reduzem as condiçóes de segurança (MORIN, 2009). Freire (1979, p. 55), já na década de 1970, afirmava que a "Educação não transforma o mundo. Educação muda as pessoas. Pessoas transformam o mundo." Assim, as pessoas precisam ser educadas, ensinadas, instruídas para que tenham açôes sustentáveis.

\section{Escolas Criativas e o compromisso com a sustentabilidade}

A realidade em que se vive exige que a ideia de sustentabilidade esteja presente em todas as disciplinas escolares, mas também na relação entre elas e delas com a realidade. Ou seja, o conteúdo deve se dinamizar a partir de práticas de pesquisa que favoreçam projeçóes e intervençóes a partir das demandas detectadas, viabilizando um conhecimento pesquisado, aprofundado, experienciado e vivido em todo o ambiente escolar e além de seus limites, visando uma generalização da sustentabilidade em suas dimensôes econômica, social, ambiental ou outras que venham a ser criadas.

O paradigma ecológico (a ideia de que se vive em uma grande casa chamada planeta Terra) torna todos dependentes, todos participantes de um lugar comum. Dessa maneira, o que afeta um europeu afetará um asiático ou um africano ou um americano, pois todos estão no mesmo espaço. Diante disso, o interesse deve ser o de manter as condiçóes necessárias para a preservação da vida de cada um e de todos (DEMARCHI, 2019).

Desse modo, o ensino deve incluir, obrigatoriamente, a discussão sobre o lugar de cada um na sociedade e, como consequência, no planeta. Deve ensinar o compromisso de cada um local e globalmente. Assim, o compromisso de cada um fortalece a ideia de todos, e educadores e educandos estarão preparados para o bem viver. Sendo isso entendido como o estado da

\footnotetext{
${ }^{5}$ Ecologia: etimologicamente construída pelo prefixo "eco", do grego "oikos", que significa lar ou casa, e pelo sufixo "logia", do grego "logos", em referência ao raciocínio ou à ciência/estudo. Assim, ecologia como estudo da casa, do lar (no sentido de lugar onde moramos, ou seja, planeta terra e tudo o que está nele).
} 
arte de viver em harmonia com os outros e com a natureza, respeitando a diversidade, repartindo com equidade, respeitando a cultura de cada povo e partilhando a técnica visando ao bem comum (DEMARCHI; OLIVEIRA NETO; ABREU, 2016).

Essa forma de pensar a educação e o ensino exige a superação dos sistemas tradicionais, baseados em aprendizado passivo, nos quais o professor ensina e o aluno aprende. Esse modelo anticriativo não busca pelo ensino e pela aprendizagem que valorizem o potencial ativo e o protagonismo do aluno, pois se centra no repasse de conhecimentos prontos apresentados pelo professor. Sem a alteração dessa ideia de educação, não há como estabelecer uma relação de ensino e de aprendizagem com a sustentabilidade.

Essa mudança de realidade exige uma educaçáo criativa, condição crucial veiculada pelas Escolas Criativas. Estas adotam um referencial de educação que estimula a análise e favorece que os estudantes elaborarem sínteses, educando-os para um processo de avaliação e autoavaliação e de produção de novas ideias (ROBINSON; ARONICA, 2019).

Nesse processo, o professor não é um transmissor de informações ou de ideias prontas, mas sua função está em acompanhar o desenvolvimento das descobertas dos estudantes, estando ao seu lado para auxiliar em suas dificuldades e promover as condiçóes para que desenvolvam as experiências necessárias a fim de formar/elaborar conceitos.

O professor contribuirá na lapidação das ideias e na avaliação do processo de construção do pensamento (GUIMARÁES, 2004). Dessa forma, colaborará como promotor do conhecimento, da construção conjunta de saberes que fundamentarão as ideias do aluno. Ao promover uma educação criativa, o professor está contribuindo com a construção de conhecimentos que estarão sempre presentes na realidade do aluno (ROBINSON; ARONICA, 2019).

A educação criativa, presente nessa perspectiva de escolas, contribui para que os alunos sejam protagonistas em sua educação, ao diagnosticar problemas enquanto projetam ou realizam intervençóes alicerçadas pelos conteúdos curriculares. Nesse processo, o simples espaço da sala de aula é pequeno para o conhecimento. Novos cenários devem ser criados, novas experiências devem ser realizadas e novas habilidades devem ser estimuladas.

Por isso, as Escolas Criativas são aquelas que transcendem sua condição de origem, valorizam os envolvidos nos processos de ensino e de 
aprendizagem, recriam suas práticas para que estas transformem a realidade enquanto são, do mesmo modo, transformadas por ela (TORRE, 2009, 2013). Essas escolas comprometem-se com aquilo que Petraglia (2013, p. 30) define como "[...] uma educação a favor dos seres humanos e da preservação da biodiversidade [...]", mediante a qual se compreende que "[...] somos e compartilhamos de uma cidadania terrestre."

Em específico sobre a sustentabilidade, conforme afirma Hülse (2020), os estudos sobre o tema não devem apenas ser bibliográficos. Os alunos devem ser estimulados a experimentar a natureza, conhecer a biodiversidade, saber a história da sua paisagem, conhecer e experimentar a geografia local, intervindo sustentavelmente nela. Nesse sentido, as iniciativas envolvendo as Escolas Criativas, especialmente no contexto catarinense, têm estimulado a exploração de cenários ecoformadores, considerados "[...] entornos acessíveis ou criados, preferivelmente, de forma colaborativa e que estimulam a interação e o protagonismo na realização de vivências/experiências para valorização das relaçôes consigo mesmo, com o outro e com o meio natural e social" (ZWIEREWICZ; SIMÃO; SILVA, 2019, p. 85).

Portanto, necessário se faz que os estudantes estejam em contato com o mundo que os cerca, vivenciando práticas pedagógicas contextualizadas e possibilitadoras de projeçóes a partir das problemáticas que permeiam a realidade, além de possíveis intervenções alicerçadas em conhecimentos curriculares. Nesse processo, facilitam-se estratégias didáticas que colaborem para vivenciar a vida econômica, política, social, cultural e ambiental.

Pensar em Escolas Criativas e, em decorrência, em educação criativa é alinhar o que é trabalhado na escola com o que acontece na sociedade. É diminuir o espaço entre o que se vivencia na escola e o que se vive no dia a dia fora dela. É trabalhar competências e habilidades para atuar sustentavelmente nessa sociedade complexa. Dessa maneira, a escola discute, analisa e promove a sustentabilidade.

Fazer uma educação criativa ou estar em uma Escola Criativa é saber que se está trabalhando com uma maneira diferente de ensinar e de aprender. Além disso, é entender que todos são diferentes e que é essa diferença que precisa ser reconhecida/valorizada, pois a escola é um espaço de aprendizagem compartilhada em que as diferenças devem ser potencializadas quando o foco é a sustentabilidade. 
Observa-se, finalmente, que a dimensão ambiental da sustentabilidade é a compatível com o proposto pelas Escolas Criativas, tanto em termos de espaços urbanos como rurais. Contudo, verifica-se também que a ideia de preservação historicamente esteve atrelada à natureza, passando ao lado dos aspectos sociais, culturais, econômicos, especialmente porque a visão sobre a qualidade de vida não se encontrava tão vinculada aos padrôes econômicos e sociais, mas, em especial, às questóes referentes ao ar que se respira.

Em contrapartida, ao se pensar em sustentabilidade, todas as possíveis dimensóes estão sendo consideradas (DEMARCHI; COSTA; MONTE, 2016), o que implica um conhecimento pertinente, ou seja, um conhecimento produzido pela racionalidade aberta e que contextualiza e concebe a multidimensionalidade humana, social e da natureza (SÁ, 2019). É essa pertinência que gera a indissociabilidade entre sustentabilidade e Escolas Criativas.

Essa condição é fortalecida pela superação de uma visão educacional que coaduna não somente com a cisão entre tempo e história, mas também entre ciência e ser humano, acirrando "[...] o individualismo e, com ele, o isolamento do sujeito” (PETRAGLIA, 2008, p. 32). Do outro lado, a ideia de sustentabilidade viabilizada pelas Escolas Criativas valoriza o estímulo ao pensamento complexo, considerado "[...] um tipo de pensamento que não separa, mas une e busca as relaçóes existentes entre os diversos aspectos da vida [...]" (PETRAGLIA, 2013, p. 16).

Vale lembrar que, para Sá $(2019$, p. 21), uma das teses nodais do pensamento complexo é a religação dos saberes e, “[...] portanto, a superação da fragmentação dos conhecimentos sobre o humano, a natureza e a sociedade." Por isso, o conhecimento pertinente é o conhecimento complexo, pois "[...] abarca a vida, abraça o objeto de estudo, o fato e o fenômeno [...]", já que "Náo há nada ou coisa ou fato que possa ser compreendido à luz do Pensamento Complexo de forma isolada. Isso porque não há nada isolado no universo."

Por isso, as Escolas Criativas têm como compromisso, entre outros, manter a integridade ecológica, reduzir as diversas formas de discriminação, preparar o cidadáo para utilizar conscientemente os recursos naturais, capacitar as pessoas para respeitarem a diversidade e estimular a produção criativa. Trata-se de uma nova forma de pensar e dinamizar a educação, comprometendo-se com o bem-estar individual, social e ambiental. 


\section{Consideraçóes finais}

A sustentabilidade deve ser estudada para que a sociedade venha a viver em consonância com o meio ambiente. Uma das formas de se estudar e ensinar a sustentabilidade é mediante o estudo de suas dimensóes. Por isso, neste artigo descreveu-se a tríplice dimensão ambiental, econômica e social, observando-se que, para se efetivar a sustentabilidade, essas dimensóes devem ser realizadas em conjunto, pois assim as pessoas e a natureza são pensadas a partir das possibilidades de convivência.

Para tanto, parte-se do princípio de que somente estudar a sustentabilidade não tem sido suficiente. É preciso vivenciá-la, e isso não é possível quando o ensino é descontextualizado, linear e fragmentado.

As iniciativas decorrentes das Escolas Criativas têm investido em práticas pedagógicas que estimulam a pesquisa, a análise, a projeção e a intervenção. Elas valorizam o desenvolvimento de competências e habilidades para realizar diagnósticos e elaborar sínteses, estimulam um processo de avaliação e de autoavaliação e colaboram para a produção de novas ideias e possíveis intervençóes enquanto valorizam a apropriação dos conteúdos curriculares.

Por meio das Escolas Criativas, estimula-se que os estudantes estejam em contato com o mundo que os cerca e as práticas sustentáveis os façam vivenciar a vida econômica, política, social, cultural e ambiental. Assim, alinha-se o que se trabalha na escola com o que acontece na sociedade.

Nesse processo, a indissociabilidade das Escolas Criativas e da sustentabilidade colabora para a integridade ecológica, reduz as diversas formas de discriminação, prepara o cidadão para utilizar conscientemente os recursos naturais, capacita as pessoas para respeitarem a diversidade e estimula a produção criativa. Nesse sentido, a sustentabilidade colabora para reconectar o ensino à natureza, os objetos de estudo aos seus ambientes e as práticas pedagógicas às diferentes formas de vida.

\section{Referências}

BOFF, Leonardo. Sustentabilidade: o que é: o que não é. $4^{\mathrm{a}}$ ed. Petrópolis: Vozes, 2015. 
BRASIL. Constituição da República Federativa do Brasil de 1988. Brasília: Senado Federal, 2019.

COLNAGO, Elizabeth de Mello Rezende. Sustentabilidade ambiental e suas dimensôes social, econômica e jurídica. Revista eletrônica [do] Tribunal Regional do Trabalho da 9a Região, Curitiba, v. 3, n. 28, p. 67-84, mar. 2014. Disponível em: https://hdl.handle.net/20.500.12178/94974. Acesso em: 2 de set. 2020 .

CRUZ, Paulo Márcio; BODNAR, Zenildo. O novo paradigma do direito na pós-modernidade. Revista de estudos constitucionais, hermenêutica e teoria do direito (RECHTD), São Leopoldo, v. 3, n. 1, p. 75-83, jan./jun. 2011. Disponível em: http://www.revistas.unisinos.br/index.php/rechtd. Acesso em: 2 set. 2020.

DEMARCHI, Clovis. Crise do estado e da democracia no contexto da globalização. Revista Jurídicas, Manizales, Colômbia, v. 16, n. 2, p. 29-44, 2019.

Disponível em: http://juridicas.ucaldas.edu.co/downloads/Juridicas16(2)_3.pdf. Acesso em: 2 set. 2020.

DEMARCHI, Clovis. Direito e Educação: a Regulação da Educação Superior no Contexto Transnacional. Jundiaí, SP: Paco Editorial, 2014.

DEMARCHI, Clovis; COSTA, Ilton Garcia da; MONTE, William Roberto Alkema do. A sustentabilidade ambiental e a dignidade da pessoa humana: catadores de material reciclável como exemplo de sua efetivação. In: DEMARCHI, Clovis et al. Direito ambiental e urbanismo [recurso eletrônico]. Itajaí: Univali, 2016. t. 2.

DEMARCHI, Clovis; OLIVEIRA NETO, Francisco J. Rodrigues de; ABREU, Pedro Manoel (org). Direito, Estado e Sustentabilidade. Livro Eletrônico. São Paulo: Intelecto Editora, 2016.

ELKINGTON, John. Sustentabilidade: canibais com garfo e faca. Trad. Laura Prades Veiga. São Paulo: M Books do Brasil Editora Ltda., 2012.

FERRER, Gabriel Real. Calidad de vida, medio ambiente, sostenibilidad y ciudadanía ¿construimos juntos el futuro? Novos estudos jurídicos - NEJ, Itajaí, v. 17, n. 3, p. 310-326, set./dez. 2013. Disponível em: 
https://siaiap32.univali.br/seer/index.php/nej/article/view/4202. Acesso em: 2 set. 2020 .

FERRER, Gabriel Real; GLASENAPP, Maikon Cristiano; CRUZ, Paulo Márcio. Sustentabilidade: um novo paradigma para o direito. Novos Estudos Jurídicos, Itajaí, v. 19, p. 1433, 2014. Disponível em: https://siaiap32.univali.br/seer/index.php/nej/article/view/4202. Acesso em: 2 set. 2020.

FREIRE, Paulo. Educação e mudança. Tradução de Moacir Gadotti e Lilian Lopes Martin. Rio de Janeiro: Paz e Terra, 1979.

FREITAS, Juarez. Sustentabilidade: direito ao futuro. Belo Horizonte: Fórum, 2011.

FROEHLICH, Cristiane. Sustentabilidade: dimensões e métodos de mensuração de resultados. Revista de gestão do Unilasalle, Canoas, v. 3, n. 3, p. 151-168, set. 2014. Disponível em: https://revistas.unilasalle.edu.br/index.php/desenvolve/article/view/1316. Acesso em: 2 set. 2020.

GARCIA, Denise Schmitt Siqueira. Dimensão econômica da sustentabilidade: uma análise com base na economia verde e a teoria do decrescimento. Veredas o Direito, Belo horizonte, v. 13, n. 15, p. 133153, jan./abr. 2016. Disponível em: http://domhelder.edu.br/revista/index.php/veredas/article/view/487. Acesso em: 3 set. 2020 .

GUIMARÁES, Mauro. A formação de Educadores Ambientais. $4^{\mathrm{a}}$ ed. Campinas: Papirus, 2004.

HÜLSE, Levi. Sustentabilidade nas Fundaçôes Privadas, Associaçôes e Cooperativas: A contribuição do associativismo para a sustentabilidade ambiental, econômica e social: análise da experiência brasileira e estrangeira. Rio de Janeiro: Lumen Juris, 2020.

HÜLSE, Levi; PASOLD, Cesar. Práticas associativas em prol da sustentabilidade em Caçador, Santa Catarina, Brasil. Revista Justiça do Direito, Passo Fundo, v. 32, n. 1, p. 170-187, 2018. Disponível em: http://seer.upf.br/index.php/rjd/article/view/8114. Acesso em: 2 set. 2020. 
MACHADO, Sulamita Crespo Carrilho. Consideraçóes sobre sustentabilidade como princípio fundamental da agenda do futuro. Persona revista electrónica de derechos existenciales, [s. l.], v. 90, n. 1, p. 8-15, jan. 2013. Disponível em: http://www.revistapersona.com.ar/. Acesso em: 2 set. 2020.

MORIN, Edgar. A cabeça bem feita: repensar a reforma, reformar o pensamento. 16 ${ }^{\mathrm{a}}$ ed. Rio de Janeiro: Bertrand Brasil, 2009.

ONU. Momento de ação global para as pessoas e para o mundo. 2015. Disponível em: https://nacoesunidas.org/pos2015/. Acesso em: 20 ago. 2020.

PASOLD, Cesar Luiz. Metodologia da Pesquisa Jurídica. Teoria e Prática. $14^{\mathrm{a}}$ ed. rev. atual. e amp. Florianópolis: EMais, 2018.

PETRAGLIA, Izabel. Pensamento complexo e educação. São Paulo: Livraria da Física, 2013.

ROBINSON, Ken; ARONICA, Lou. Escolas criativas: a revolução que está transformando a educação. Tradução de Luís Fernando Marques Dorvillé. Porto Alegre: Penso, 2019.

SÁ, Ricardo Antunes. Contribuiçôes teórico-metodológicas do pensamento complexo para a construção de uma pedagogia complexa. In: SÁ, Ricardo Antunes; BEHRENS, Marilda Aparecida (org.). Teoria da complexidade: contribuiçóes epistemológicas para uma pedagogia complexa. Curitiba: Appris, 2019. p. 17-64.

SACHS, Ignacy. Caminhos para o desenvolvimento sustentável. 2a ed. Rio de Janeiro: Garamond, 2002.

SACHS, Ignacy.. Desarrollo sustentable, bio-industrialización descentralizada y nuevas configuraciones ruralurbanas: Los casos de India y Brasil. Pensamiento Iberoamericano, Madrid, v. 46, p. 235-256, 1990.

SILVA, Antonio Sergio; SOUZA, José Gilberto de; LEAL, Antonio Cezar. A sustentabilidade e suas dimensóes como fundamento da qualidade de vida. Revista geografia em atos GEOATOS, Presidente Prudente, v. 1, n. 12, p. 22-42, jan./dez. 2012. Disponível em: http://revista.fct.unesp.br/index.php/geografiaematos/article/view/1724. Acesso em: 2 set. 2020. 
SOUZA, Maria Claudia da Silva Antunes de. Sustentabilidade corporativa: uma iniciativa de cunho social transformando o meio ambiente. Revista jurídica Unicuritiba, Curitiba, v. 4, n. 45, p. 245-262, jan./dez. 2016. Disponível em: http://revista.unicuritiba.edu.br/index.php/revjur/issue/view/102. Acesso em: 2 set. 2020 .

STROH, Paula Yone (org.). Iganacy Sachs: caminhos para o desenvolvimento sustentável. Rio de Janeiro: Garamond, 2009.

TONNERA JUNIOR, João. Sustentabilidade(s) e os direitos sociais. Rio de Janeiro: Lumem Juris, 2016.

TORRE, Saturnino de la. Escolas criativas: escolas que aprendem, criam e inovam. In: ZWIEREWICZ, Marlene; TORRE, Saturnino de la. (org.). Uma escola para o século XXI: Escolas Criativas e resiliência na educação. Florianópolis: Insular, 2009. p. 55-69.

TORRE, Saturnino de la. Movimento de escolas criativas: fazendo parte da história de formação e transformação. In: ZWIEREWICZ, Marlene. (org.). Criatividade e inovação no Ensino Superior: experiências latino-americanas e europeias em foco. Blumenau: Nova Letra, 2013. p. 139-162.

VEIGA, José Eli da. Para entender o desenvolvimento sustentável. São Paulo: Ed. 34, 2015.

ZWIEREWICZ, Marlene; SIMÃO, Vera Lúcia; SOUZA e SILVA, Vera Lúcia de. Da formação docente ao protagonismo infantil na criação de cenários ecoformadores. Revista Electrónica de Investigación y Docencia (REID), [s. l.], v. 4, p. 83-94, 2019. Doi: 10.17561/reid.m4.6. Disponível em:

https://revistaselectronicas.ujaen.es/index.php/reid/article/view/5017/4441. Acesso em: 10 jan. 2020.

Recebido em: 14 ago. 2020

Aceito em: 27 ago. 2020 